\title{
Study of Load Fluctuation Characteristics of PDC Bit during Gas Extraction Borehole in Soft Coal Seam
}

\author{
Shifeng Wang, Xiaoming Han*, Qiangqiang Zhang \\ School of Mechanical and Power Engineering, Henan Polytechnic University, Jiaozuo, China \\ Email: 99491196@qq.com, *hanxmr@126.com
}

How to cite this paper: Wang, S.F., Han, X.M. and Zhang, Q.Q. (2017) Study of Load Fluctuation Characteristics of PDC Bit during Gas Extraction Borehole in Soft Coal Seam. Open Access Library Journal, 4: e3693.

https://doi.org/10.4236/oalib.1103693

Received: May 26, 2017

Accepted: June 22, 2017

Published: June 26, 2017

Copyright $\odot 2017$ by authors and Open Access Library Inc.

This work is licensed under the Creative Commons Attribution International License (CC BY 4.0).

http://creativecommons.org/licenses/by/4.0/

\begin{abstract}
Load fluctuation characteristics have a great influence on drilling performance. So, study the influence of drilling kinematic parameters on the load fluctuation characteristics of PDC bit becomes more and more important. Gas drainage drilling experiment table was built and Gas drainage drilling experiment was carried out under different feed speed, different rotation speed and same drilling thickness with different feed speed and rotation speed. The results indicate that drilling torque decreases with the increase of rotation speed; vibration amplitude of drilling torque increases with increase of rotation speed. Vibration amplitude of feed resistance decreases from $90 \mathrm{r} / \mathrm{min}$ to about $240 \mathrm{r} / \mathrm{min}$ and then increases. The value of $240 \mathrm{r} / \mathrm{min}$ is minimum. Feed resistance and drilling torque increase with the increase of feeding speed. Vibration amplitude of drilling torque and feeding resistance increases with the increase of feeding speed. Feed resistance and drilling torque are almost equal with the same drilling thickness; meanwhile, vibration amplitude of drilling torque and feed resistance increases with the increase of feeding speed. It provides a good basis for setting the appropriate feeding speed and rotation speed in actual work.
\end{abstract}

\section{Subject Areas}

Mechanical Engineering

\section{Keywords}

Load Fluctuation Characteristics, Feeding Resistance, Drilling Torque, Soft Coal, Vibration Amplitude

\section{Introduction}

All metallurgical and mechanical aspects of failure that can occur for a drill pipe 
are considered and discussed. And finally, this comprehensive review leads to a conclusion that categorizes the primary sources of drill pipe failure into seven major groups and makes some recommendations to avoid them [1]. The critical stress value for sulfide stress corrosion cracking of the drill pipe material is obtained, and the mechanisms of axial cracking failure and corresponding preventive measures are proposed [2]. Drilling performance and durability of polycrystalline diamond compact (PDC) bits can be degraded by the vibrations associated with drilling. In particular, two types of vibrations are of interest: torsional oscillation and backward whirl. Torsional oscillation (also referred to as "stick/ slip") is characterized by fluctuations in bit angular velocity [3]. The ANASYS software was applied to analyze the inherent frequencies of the vertical vibration, horizontal vibration and rotary vibration during the different drilling depth. The excitation frequency to the drilling rod could be changed by the rotary speed adjusted at drilling rig working period. Thus the resonance caused by the vibration could be reduced and could provide the guidance to the success of the geological exploration [4]. Transverse vibrations of drillstrings caused by axial loading and impact with the wellbore wall are studied [5]. A linear quadratic regulator (LQR) controller is designed based on a linearized model and is shown to be effective in eliminating this type of oscillations. It is also shown that for some operational parameters the control action may excite large bending vibrations due to coupling with the torsional motion [6]. With an increase in borehole pressure, the side crack length decreases significantly; furthermore, the main mode of rock failure shifts from tension to shear [7]. The fractal dimension of cracks in the coal seam roofing is affected by the thickness of coal seam, spacing of coal seam and the lithological characteristics of overlying rock strata. With the increase of the thickness of coal seam (composite thickness of coal seam), the fractal dimension of cracks increases [8]. The cutting efficiency of the PDC bit has been analyzed based on the development of an analytical single PDC cutter force model. The cutting efficiency of a single PDC cutter is defined as the ratio of the volume removed by a cutter over the force required to remove that volume of rock [9]. The capability of several types of flat PDC cutters to withstand combined loads was tested and evaluated by the impact and cutting of single PDC cutter on granite in a linear impact-cutting Table. The primary failure modes of PDC cutters withstanding different combined loads were investigated and analyzed [10]. The relationship among Roller shape, material factors and roller movement parameters was researched according to experiment of combining Finite Element Method, the results indicated that cutting shape feature was an important factor that affects the efficiency of cutting. The cutting temperature between the geometry of the cutter and the rotating speed of the roller were a function. The cutting efficiency of the cylinder was affected by the geometry of the cylinder [11] [12] [13]. Finite element modeling of the PDC bit cutting pick was researched, the results indicated that when cutting thickness is $(0.5-1.0) \mathrm{mm}$, the average cutting force reduces. When the cutting thickness is more than $2 \mathrm{~mm}$, the average cutting force is the same [14]. A new cutter-rock 
interaction model was built and prediction accuracy of wellbore deviation was greatly improved was obtained [15]. Dynamic process of single cutterdrills rock under different drilling depth was analyzed, cutting force curve was built [16]. A new model that was used to research the failure case of PDC bit was built according to real date [17]. The force-balanced condition of a PDC bit withsingle-set cutters may be violated during transit-formation drilling was found. A new cutter layout procedure is proposed, which not only ensures the force-balanced condition during transit drilling but also significantly improves drilling efficiency [18]. When the front rake angle is between $15^{\circ}$ and $20^{\circ}$, the rockbreaking effect of the PDC bit cutter is desirable. When the side rake angle is $5^{\circ}$, the rock-breaking effect is best and the probability of tooth damage is relatively low [19]. The model among the cutting influence, cutting thickness, cutting pitch and cutting mechanism was built according to Influence of cutting mechanism on the cutting influence and failure form of cutting coal seams [20].

In order to increase the drilling performer of PDC bit, lots of research have been done, however, papers about study on the influence of PDC bit drilling kinematic parameters (include feed speed, rotation speed, same drilling thickness) on drill pipe vibration under confining pressure in Gas Drainageis few. So drilling experiment table is built and carried out under confining pressure and different drilling parameters. In this paper, influence of PDC bit drilling kinematic parameters on Drill pipe vibration is researched and some conclusions are obtained.

\section{Specific Energy Consumption Analyze of PDC Bit during Gas Extraction Borehole}

\subsection{Force Analyze of Spliced Variant}

Cutting mechanism of PDC bit is that the cutter can automatically cut the coal seams under the drilling pressure. Cutters cutting coal rock under the action of torque. The two dimensional force model was established according to the analysis of shear broken coal rock is shown in Figure 1 and Figure 2. Spliced variant

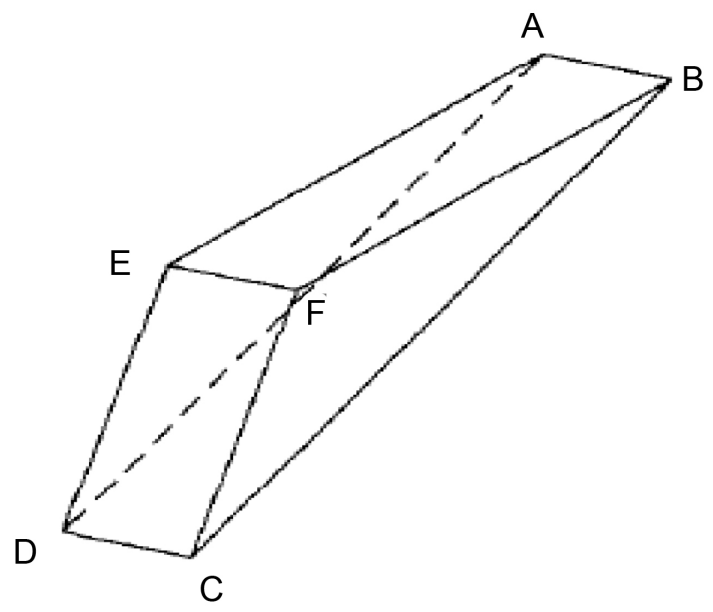

Figure 1. Spliced variant. 


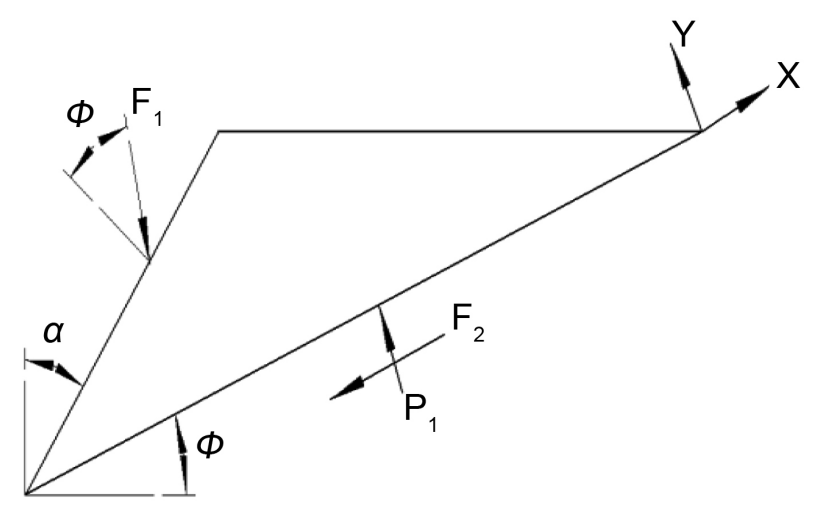

Figure 2. Analysis of spliced variant of coal rock.

of coal rock was researched under the coal rock properties $(\theta, \psi, \phi)$ was determined. The relationship between the contact normal pressure and the rake angle of the cutter was researched. Normal pressure is on the contact surface, resultant force is $F_{1}$, reaction force $P_{1}$, vertical force $P_{2}$ is on the shear plane. Rake angle of cutter is $\alpha$, the friction angle is $\theta$, the included angle between the cutting surface of coal and the feed direction of the cutter is $\phi$, Internal friction angle of coal and rock is $\phi$, shear surfaces is $S\left(S_{A B C D}\right)$.

$$
P_{1}=\int \sigma_{n} \mathrm{~d} s, F_{2}=\int \tau \mathrm{d} s
$$

Average shear force; $\tau=C+\sigma_{n} \tan \phi$ is taken into (2-1);

$$
F_{2}=C \cdot S+P_{1} \tan \phi
$$

where: $C$ is cohesion of coal rock, $\sigma_{n}$ is anti-crushing strength, $\tau$ is the residual shear force. According to the two directions of the coordinate axes, the equilibrium condition is available under the limit equilibrium state.

$$
\begin{aligned}
& \sum X=0, \quad F_{1} \sin \left(\frac{\pi}{2}-\alpha-\psi-\theta\right)-F_{2}=0 \\
& \sum Y=0, \quad P_{1}-F_{1} \sin \left(\frac{\pi}{2}-\alpha-\psi-\theta\right)=0
\end{aligned}
$$

$(2-2)$ is taken into (2-3), (2-4)

$$
F_{1}=\frac{C \cdot S \cdot \cos \phi}{\cos (\phi+\psi+\theta+\alpha)}
$$

$s=b \cdot b_{0} ; b$ is width of cutter drill coal and rock in Figure 3 and $b_{0}$ is crack length(AD in Figure 1), Figure 4 is PDC bit.

$$
\begin{aligned}
& F_{1}=\frac{C \cdot b \cdot b_{0} \cos \phi}{\cos (\phi+\psi+\theta+\alpha)} \\
& b=2 \sqrt{R^{2}+\left(R-\frac{h}{3 \cos \alpha}\right)^{2}}
\end{aligned}
$$

$b$ is drilling width, $h$ is drilling thickness $(h=v / n), v$ is feeding speed $(\mathrm{m} /$ $\min ), n$ is Rotating speed of bit $(\mathrm{r} / \mathrm{min})$.

When $\alpha+\psi+\theta+\phi \geq \pi / 2, \quad F_{1}$ is infinity or negative. The contact area 


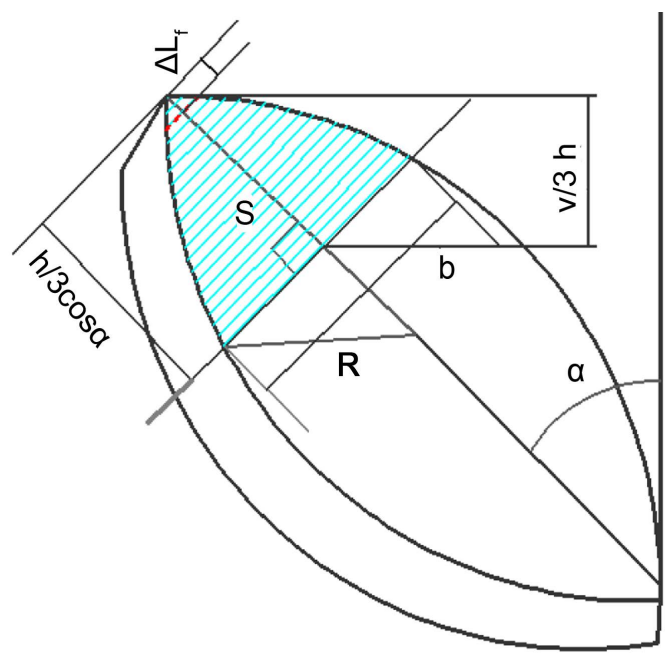

Figure 3. Sketch map of cutting area.

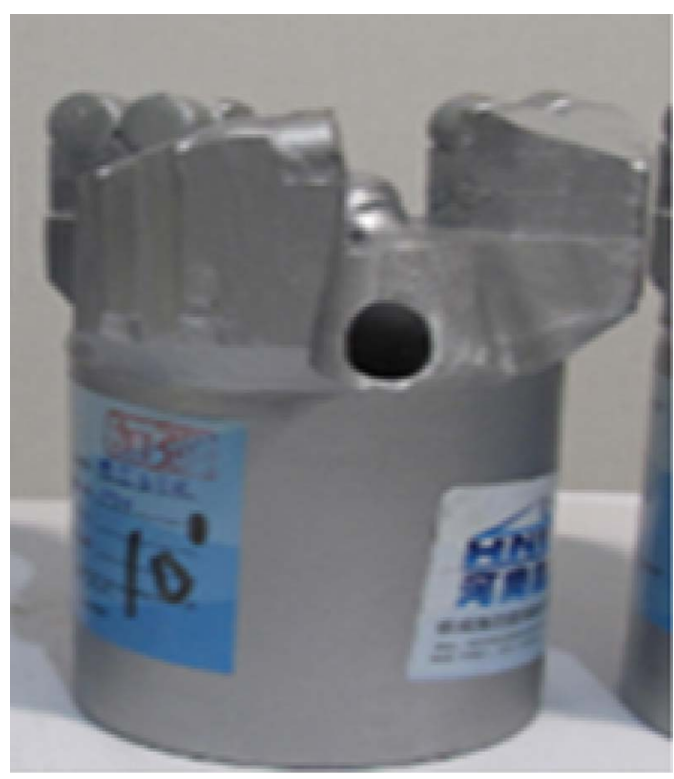

Figure 4. PDCbit.

between the cutter and the coal rock increases with the increase of rake angle, so strong extrusion is occurred on coal rock. Shear failure is not occurred, and extrusion failure is occurred. Since the uniaxial compressive strength of the coal rock is much larger than that of the shear strength, the fragmentation of coal and rock need more drilling pressure and tangential force. Drilling efficiency is very low, so the affective range of the rake angle is $0 \leq \alpha \leq \pi / 2-(\psi+\theta+\phi)$.

\subsection{Analysis of Cutting Force of Cutter and Specific Energy Consumption}

Cutting force, drilling pressure, The reaction force of rock to cutter is $F_{1}$, friction $F_{3}$ and contact normal pressure $P_{2}$ are shown in Figure 5.

The coefficient of friction between the coal and the tangent plane is $\mu$, $F_{3}=\mu P_{2}$, Balance principle of force: 


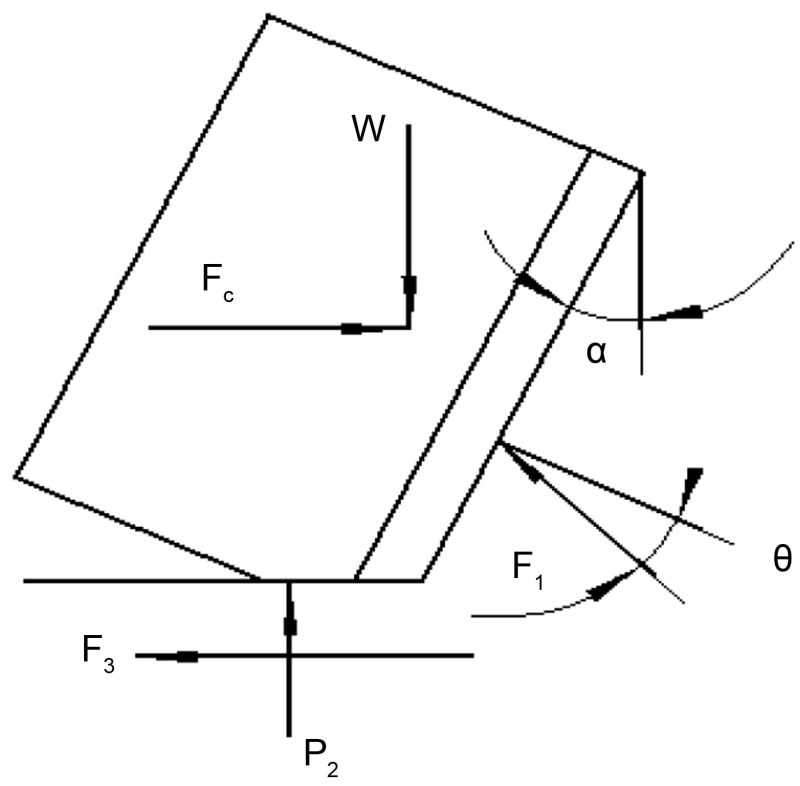

Figure 5. Cutter force analysis.

$$
\begin{gathered}
F_{c}=F_{1} \cos (\theta+\alpha)+\mu P_{2} \\
W=F_{1} \sin (\theta+\alpha)+P_{2}
\end{gathered}
$$

$F_{c}$ is cutting force, $W$ is feeding resistance, $P_{2}$ is related to the force distribution on the wear surface.

$$
P_{2}=b \cdot \sigma_{s} \cdot\left[\frac{0.6}{\cos \alpha}+\frac{1}{3}\left(\Delta L_{f}-\frac{0.6}{\cos \alpha}\right)\right][21]
$$

$\Delta L_{f}$-PDC cutter wear length. $R$ is the radius of cutter, $\sigma_{s}$ is uniaxial compression yield force of coal, usually the value is tenfold than coal Platt factor, $\sigma_{s}=10 f, f$ is coal rock hardness.

(2-6) and (2-7) are brought into the (2-8):

$$
\begin{aligned}
W= & \frac{2 C b_{0} \sqrt{R^{2}+\left(R-\frac{v}{3 n \cos \alpha}\right)^{2}} \cdot \cos \phi \cdot \sin (\theta+\alpha)}{\cos (\psi+\alpha+\theta+\phi)} \\
& +b \cdot \sigma_{s}\left[\frac{0.6}{\cos \alpha}+\frac{1}{3}\left(\Delta L_{f}-\frac{0.6}{\cos \alpha}\right)\right] \\
F_{c}= & \frac{2 C b_{0} \sqrt{R^{2}+\left(R-\frac{v}{3 n \cos \alpha}\right)^{2}} \cdot \cos \phi \cdot \cos (\theta+\alpha)}{\cos (\psi+\alpha+\theta+\phi)} \\
& +\mu b \cdot \sigma_{s}\left[\frac{0.6}{\cos \alpha}+\frac{1}{3}\left(\Delta L_{f}-\frac{0.6}{\cos \alpha}\right)\right]
\end{aligned}
$$

It's obvious drilling torque and feeding resistance are not only correlated with rake angle, cutting condition, but also correlates with feed speed and rotating speed. This paper studies load fluctuation characteristics of PDC bit during gas extraction borehole in soft coal seam. 


\section{Drilling Experiment Table Is Built}

\subsection{Test Bench}

According to the theory of rock cutting and breaking, the establishment of the gas drainage drilling test bench (Figure 6) is built. The test bench mainly has two parts, the power system and the testing system. The test rig drilling experiments is not only used in drilling coal rock with PDC bit, but also in a variety of types of bits drilling test.

\subsubsection{Power System}

The dynamic system of the test bench adopts ZDY1900S full hydraulic drilling machine. The rig is mainly composed of a host machine, pumping station and control station. Pump station is driven by the motor rotation, the hydraulic oil will be transferred to the feed passage and the rotary actuator, the control console on the pole realizes the drill rotation and feed. The drilling machine not only provides power for the drilling tool, but also provides the confining pressure load for the confining pressure loading device on the top of the coal wall support. At the top of the coal wall support, HSG90/63 engineering hydraulic cylinder is provided, the rated working pressure of the hydraulic cylinder is $16 \mathrm{MPa}$, and the stroke is $640 \mathrm{~mm}$, so as to meet the requirement of applying the confining pressure to the coal wall. The hydraulic circuit of the hydraulic circuit is additionally provided with two-way hydraulic lock, so as to ensure the stablity of the confining pressure in the operation of the hydraulic cylinder.

\subsubsection{Test System}

YSV dynamic signal acquisition and analysis software were used in testing system

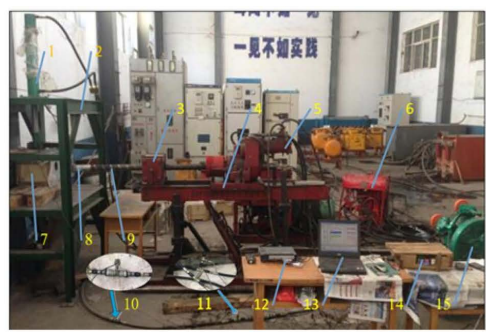

1-fluid cylinder; 2-coal wall support; 3-clamper; 4-advanced gear; 5-gyroscope; 6-control Table; 7-test coal wall; 8-drilling bit; 9-drill pipe; 10-flow sensor; 11-pressure pickup; 12-data acquisition; 13-display interface; 14-flow digital display meter; 15-draught fan

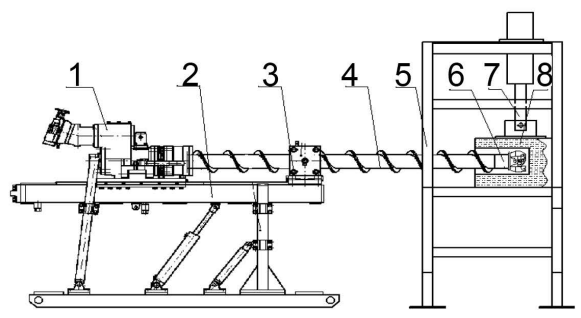

1-clinostat; 2-feeding device; 3-clamping device; 4-drill pipe; 5-coal wall support; 6-PDC bit; 7-hydraulic cylinder; 8-test coal wall

Figure 6. Gas drainage drilling experiment table. 
for drilling test data acquisition system; FST800-201G222A-16B pressure sensors are arranged in the hydraulic motor and hydraulic cylinder oil import to drill drilling torque to tests the feed resistance signal. The main performance parameters of the sensor: range: 0 - 31.5 Mpa; sensitivity: 158.73 output voltage: 0 - 5 $\mathrm{V}$; standard engineering unit: $\mathrm{mv} / \mathrm{Mpa}$; measurement accuracy: $0.5 \% \mathrm{FS}$; the flow of the hydraulic system using the model for the turbine flow sensor LWGY-15A, the nominal pressure 6.4 MPa, maximum pressure loss is 0.0035 $\mathrm{MPa}$, the turbine flow sensor and the hydraulic motor return oil pressure sensor on the pipeline in series.

According to the above power system and the test system composed of drilling test bench, provide the maximum torque of $1900 \mathrm{Nm}$ and maximum speed of $300 \mathrm{r} / \mathrm{min}$, to the process of $600 \mathrm{~mm}$. According to the working performance of the drilling rig, the displacement of the main oil pump in the pump station is changed to change the rotating speed of the drilling machine. The speed range of the drill bit is $85-300 \mathrm{r} / \mathrm{min}$. Adjust the displacement of the auxiliary oil pump in the pump station to change the feed rate of the drilling mechanism. The feed rate range of drilling mechanism is $0-3 \mathrm{~m} / \mathrm{min}$.

\section{Influence of Drilling Kinematic Parameters on Load Fluctuation Characteristics}

\subsection{Influence of Rotation Speed on Load Fluctuation Characteristics}

To research the influence of rotation speeds on load fluctuation, drilling coal rock experiment is carried out under different rotation speeds. Working condition parameters in the process of drilling coal rock are as follows: protodyakonov coefficient of coal is $\mathrm{f}: \mathrm{f}=1.03$, confining pressure is $7 \mathrm{MPa}$, feed speed is 0.7 $\mathrm{m} / \mathrm{min}$, rake angle of PDC bit is $15^{\circ}$, rotation speed is $90 \mathrm{r} / \mathrm{min}, 140 \mathrm{r} / \mathrm{min}, 190$ $\mathrm{r} / \mathrm{min}, 240 \mathrm{r} / \mathrm{min}$ and $290 \mathrm{r} / \mathrm{min}$. Feeding resistance and drilling torque is got under different rotation speed is shown in Table 1. Figure 7 and Figure 8 show influence of rotation speed on load fluctuation characteristics.

Table 1, Figure 7 and Figure 8 show drilling torque and feed resistance are decreased with the increase of rotation speed. Vibration amplitude of drilling torque increases with increase of rotation speed. Vibration amplitude of feed resistance decreases from $90 \mathrm{r} / \mathrm{min}$ to $240 \mathrm{r} / \mathrm{min}$ then increases. The value of 240

Table 1. Feed resistance and drilling torque under different rotation speed.

\begin{tabular}{ccccccc}
\hline \multirow{2}{*}{$\begin{array}{c}\text { Rotation } \\
\text { speed } \\
(\mathrm{r} / \mathrm{min})\end{array}$} & $\begin{array}{c}\text { Maximum } \\
\text { value } \\
(\mathrm{N} \cdot \mathrm{m})\end{array}$ & $\begin{array}{c}\text { average } \\
\text { value } \\
(\mathrm{N} \cdot \mathrm{m})\end{array}$ & $\begin{array}{c}\text { standard } \\
\text { deviation }\end{array}$ & $\begin{array}{c}\text { Maximum } \\
\text { value }(\mathrm{KN})\end{array}$ & $\begin{array}{c}\text { Feeding resistance }(\mathrm{KN}) \\
\text { avalue }(\mathrm{KN})\end{array}$ & $\begin{array}{c}\text { deviation } \\
\text { deve }\end{array}$ \\
\cline { 2 - 7 } 90 & 552.8 & 525.6 & 12.4 & 6.95 & 5.77 & 0.56 \\
140 & 469.4 & 420.6 & 14.7 & 6.14 & 5.35 & 0.45 \\
190 & 373.7 & 344.3 & 15.3 & 4.82 & 4.12 & 0.41 \\
240 & 337.3 & 309.5 & 15.7 & 4.22 & 3.66 & 0.23 \\
290 & 221.8 & 178.4 & 16.8 & 2.86 & 2.86 & 0.53 \\
\hline
\end{tabular}




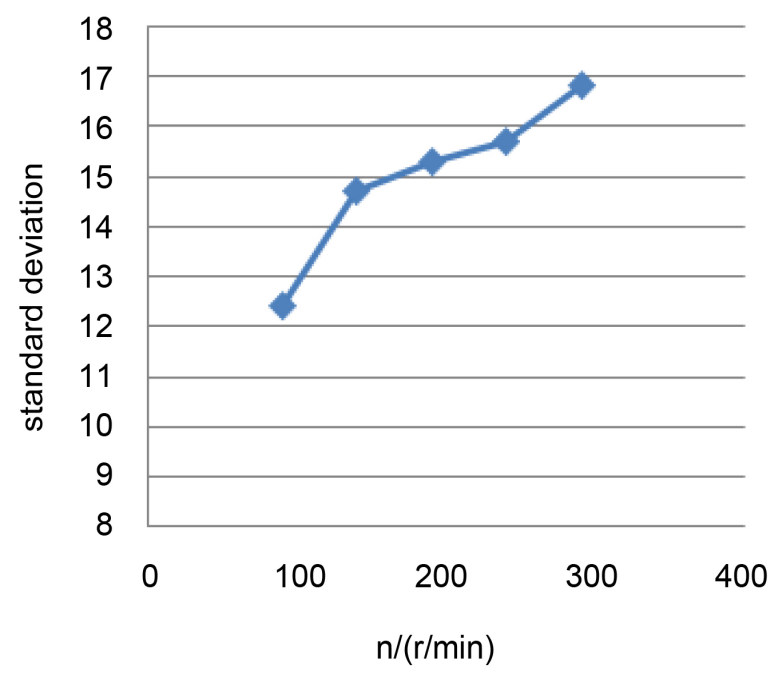

Figure 7. Influence of rotation speed on drilling torque's load fluctuation characteristics.

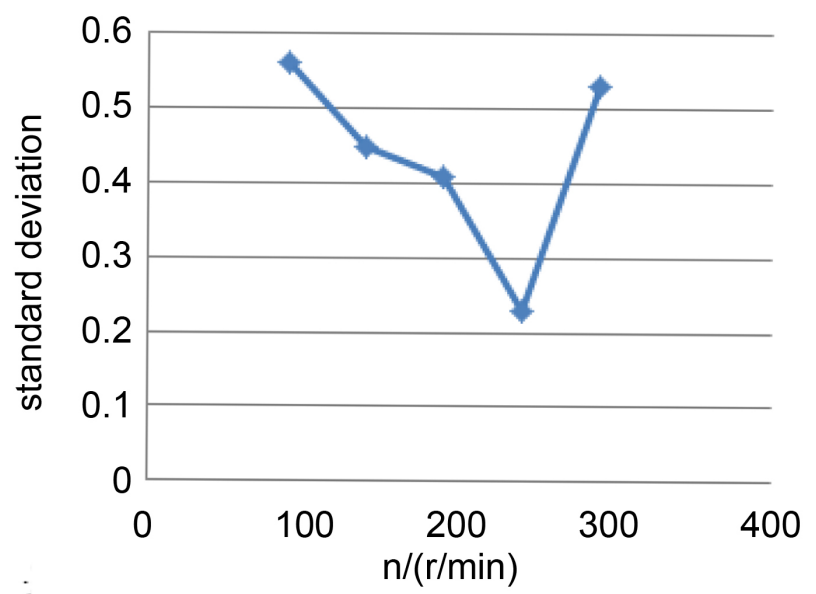

Figure 8. Influence of rotation speed on feeding resistance's load fluctuation characteristics.

$\mathrm{r} / \mathrm{min}$ is Minimum.

\subsection{Influence of Feed Speed on Load Fluctuation Characteristics}

In order to research the influence of feed speeds on load fluctuation, drilling coal rock experiment is carried out under different rotation speeds. Working condition parameters in the process of drilling coal rock are as follows; Rotation speed is $290 \mathrm{r} / \mathrm{min}$, Plattcoefficientf $=1.03$ experimental coal wall, confining pressure is $7 \mathrm{MPa}$, bit rake angle of PDC bits is $10^{\circ}$, feeding speed is $0.3 \mathrm{~m} / \mathrm{min}, 0.5 \mathrm{~m} / \mathrm{min}$ and $0.7 \mathrm{~m} / \mathrm{min}$. Feed resistance and drilling torque is got under different rotation speed is shown in Table 2. Figure 9 and Figure 10 show influence of feeding speed on load fluctuation characteristics.

Table 2, Figure 9 and Figure 10 show feed resistance and drilling torque increase with the increase of feed speed. Vibration amplitude of drilling torque and feed resistance increase with the increase of feeding speed. 
Table 2. Feed resistance and drilling torque under different feeding speed.

\begin{tabular}{ccccccc}
\hline \multirow{2}{*}{$\begin{array}{c}\text { Feeding } \\
\text { speed } \\
(\mathrm{m} / \mathrm{min})\end{array}$} & $\begin{array}{c}\text { Maximum } \\
\text { value } \\
(\mathrm{N} \cdot \mathrm{m})\end{array}$ & $\begin{array}{c}\text { average } \\
\text { value } \\
(\mathrm{N} \cdot \mathrm{m})\end{array}$ & $\begin{array}{c}\text { standard } \\
\text { deviation }\end{array}$ & $\begin{array}{c}\text { Maximum } \\
\text { value }(\mathrm{KN})\end{array}$ & $\begin{array}{c}\text { Fverage } \\
\text { value }(\mathrm{KN})\end{array}$ & $\begin{array}{c}\text { standard } \\
\text { deviation }\end{array}$ \\
\hline 0.3 & 358.7 & 344.6 & 11.6 & 1.61 & 1.44 & 0.20 \\
0.5 & 384.3 & 366.4 & 14.3 & 5.0 & 2.55 & 1.11 \\
0.7 & 421.6 & 356.1 & 15.3 & 4.6 & 3.56 & 1.56 \\
0.9 & 423.6 & 399.6 & 20.6 & 6.0 & 4.11 & 2.30 \\
\hline
\end{tabular}

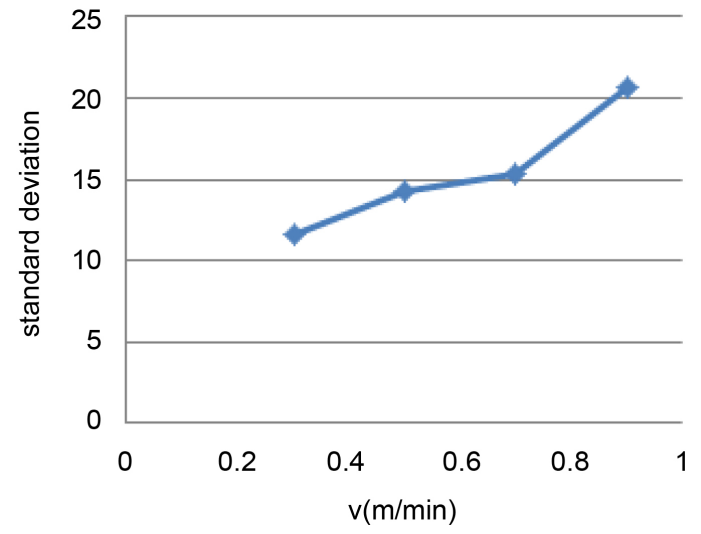

Figure 9. Influence of feeding speed on drilling torque's load fluctuation characteristics.

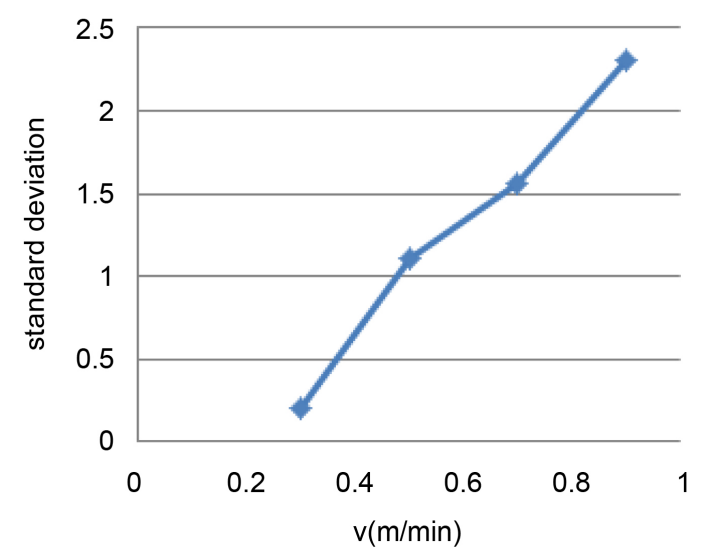

Figure 10. Influence of feeding speed on feeding resistance's load fluctuation characteristics.

\subsection{Influence of Same Drilling Thickness on Load Fluctuation Characteristics}

In order to research the influence of same drilling thickness on Load fluctuation, drilling coal rock experiment is carried out under different rotation speeds. Working condition parameters in the process of drilling coal rock are as follows; drilling thickness $\mathrm{h}=\mathrm{v} / \mathrm{n}=2.63 \mathrm{~mm} / \mathrm{r}$, protodyakonov coefficient of coal is $\mathrm{f}: \mathrm{f}=$ 2.2:, confining pressure is $7 \mathrm{MPa}$, rotation speeds are $290 \mathrm{r} / \mathrm{min}, 240 \mathrm{r} / \mathrm{min}, 190$ $\mathrm{r} / \mathrm{min}, 140 \mathrm{r} / \mathrm{min}$, rake angle of PDC bit is $15^{\circ}$. Feeding speed are $0.76 \mathrm{~m} / \mathrm{min}$, 
$0.63 \mathrm{~m} / \mathrm{min}, 0.37 \mathrm{~m} / \mathrm{min}, 0.24 \mathrm{~m} / \mathrm{min}$. Feed resistance and drilling torque is got under different combinations is shown in Table 3. Figure 11 and Figure 12 show influence of different combination on load fluctuation characteristics.

Table 3, Figure 11 and Figure 12 show that feed resistance and drilling torque is almost equal with the same drilling thickness, but vibration amplitude of drilling torque and feed resistance increase with the increase of feed speed.

Table 3. Feed resistance and drilling torque under different combination.

\begin{tabular}{ccccccc}
\hline \multirow{2}{*}{$\begin{array}{c}\text { Feeding } \\
\text { speed } \\
(\mathrm{m} / \mathrm{min})\end{array}$} & $\begin{array}{c}\text { Maximum } \\
\text { value } \\
(\mathrm{N} \cdot \mathrm{m})\end{array}$ & $\begin{array}{c}\text { Dverage } \\
\text { value } \\
(\mathrm{N} \cdot \mathrm{m})\end{array}$ & $\begin{array}{c}\text { Dtandard } \\
\text { deviation }\end{array}$ & $\begin{array}{c}\text { Maximum } \\
\text { value }(\mathrm{KN})\end{array}$ & $\begin{array}{c}\text { Feeding resistance }(\mathrm{KN}) \\
\text { value }(\mathrm{KN})\end{array}$ & $\begin{array}{c}\text { deviation } \\
\text { standard }\end{array}$ \\
\hline 0.24 & 570.2 & 525.5 & 15.7 & 3.61 & 3.52 & 0.08 \\
0.37 & 580.1 & 530.7 & 19.8 & 3.63 & 3.51 & 0.10 \\
0.63 & 541.3 & 520.4 & 20.7 & 4.21 & 3.65 & 0.28 \\
0.76 & 544.2 & 518.9 & 23.9 & 5.82 & 3.63 & 0.31
\end{tabular}

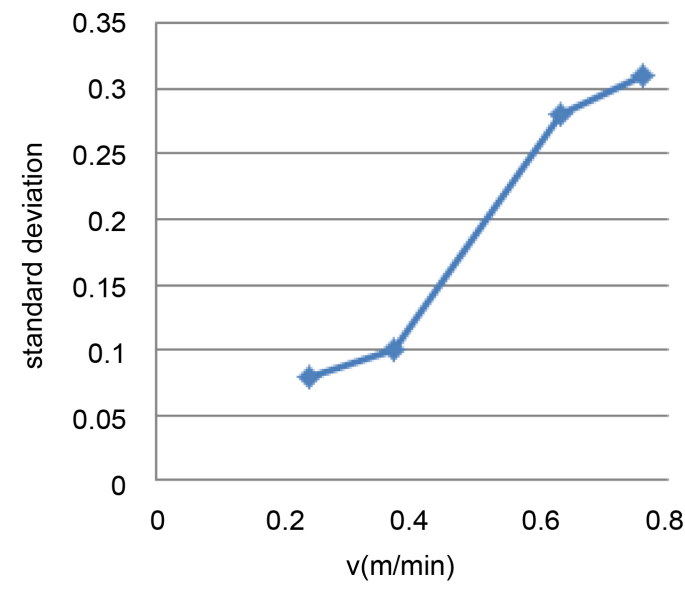

Figure 11. Influence of different combination on feeding resistance's load fluctuation characteristics.

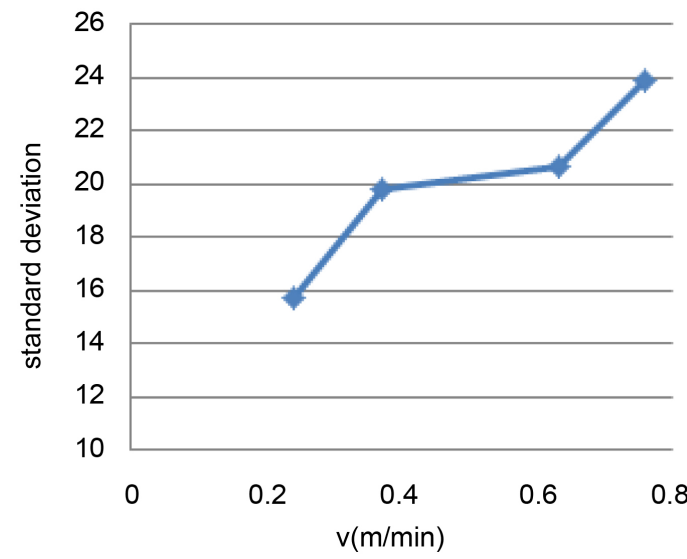

Figure 12. Influence of different combination on drilling torque's load fluctuation characteristics. 


\section{Conclusion}

Load fluctuation characteristics have a great influence on drilling performance. So, study the influence of drilling kinematic parameters on load fluctuation characteristics of PDC bit becomes more and more important. Gas drainage drilling experiment table is built and carried out under different feeding speed, different rotation speeds and same drilling thickness with different feed speeds and rotation speeds. Drilling torque and feed resistance are decreased with the increase of rotation speed. Vibration amplitude of drilling torque increases with increase of rotation speed. Vibration amplitude of feed resistance decreases from 90 $\mathrm{r} / \mathrm{min}$ to $240 \mathrm{r} / \mathrm{min}$ then increases. The value of $240 \mathrm{r} / \mathrm{min}$ is Minimum. Feed resistance and drilling torque increase with the increase of feed speed. Vibration amplitude of drilling torque and feeding resistance increases with the increase of feeding speed. Feed resistance and drilling torque are almost equal with the same drilling thickness; meanwhile, vibration amplitude of drilling torque and feed resistance increase with the increase of feeding speed. According to the paper, the relationship between kinematic parameter and vibration amplitude of drilling torque and feed resistance was analyzed and load fluctuation characteristics of PDC bit during gas extraction borehole in soft coal seam was analyzed. It provides a good basis for setting the appropriate feeding speed and rotation speed in actual work to avoid blocking which caused by excessive vibration and improve work efficiency. In the paper, vibration amplitude of drilling torque and feed resistance was researched, but many forms of vibration include torsional vibration, longitudinal vibration and lateral vibration during drilling drills coal rock, study these forms is next important task.

\section{Acknowledgements}

This research was financially supported by the Henan province science and technology project (Grant No. 162102210229), China Postdoctoral Science Foundation Funded Project (Grant No. 2016M592289) and Henan province education department applied research project fund (Grant No. 15A440004 and 16A460005).

\section{References}

[1] Zamani, S.M., Hassanzadeh-Tabrizi, S.A. and Sharifi, H. (2016) Failure Analysis of Drill Pipe: A Review. Engineering Failure Analysis, 59, 605-623. https://doi.org/10.1016/j.engfailanal.2015.10.012

[2] Liu, Y., Lian, Z., Lin, T., Shen, Y. and Zhang, Q. (2016) A Study on Axial Cracking Failure of Drill Pipe Body. Engineering Failure Analysis, 59, 434-443.

https://doi.org/10.1016/j.engfailanal.2015.11.004

[3] Makkar, N. and Sullivan, E.C. (2014) Coupling between Lateral and Torsional Oscillations: A New Insight into PDC Drilling Inefficiencies. Offshore Technology Conference Asia, 3, 25-28.

[4] Zhang, J.C., Duan, L.C. and Wang, H.B. (2009) Analysis on Drilling Rod Vibration Mode of Coalfield Geological Exploration Based on Ansys. Coal Science and Technology, 8, 64-66. 
[5] Yigit, A.S. and Christoforou, A.P. (1996) Coupled Axial and Transverse Vibrations of Oilwell Drillstrings. Journal of Sound and Vibration, 195, 617-627. https://doi.org/10.1006/jsvi.1996.0450

[6] Yigit, A.S., and Christoforou, A.P. (2000) Coupled Torsional and Bending Vibrations of Actively Controlled Drillstrings. Journal of Sound and Vibration, 234, 67-83. https://doi.org/10.1006/jsvi.1999.2854

[7] Shi, X., Cai, W., Meng, Y., Jin, W., Li, G. and Tao, Z. (2014) Numerical Study of Effects of Borehole Pressure on Bit-Teeth Induced Rock Fragmentation. Electronic Journal of Geotechnical Engineering, 19, 4743-4752.

[8] Hu, Y.Z., Liu, C.Y. and Li, J.W. (2015) Fractal Analysis of Cracks Due to Mixed Mining of Coal Seam Group. Electronic Journal of Geotechnical Engineering, 20, 9749-9760.

[9] Hareland, G., Nygaard, R., Yan, W. and Wise, J.L. (2007) Cutting Efficiency of a Single PDC Cutter on Hard Rock. Journal of Canadian Petroleum Technology, 48, 60-65. https://doi.org/10.2118/09-06-60

[10] Li, X.B. and Zhao, F.J. (2002) Failure Modes of PDC Cutters under Different Loads. Chinese Journal of Nonferrous Metals, 12, 504-507.

[11] Mishra, B. (2007) Analysis of Cutting Parameters and Heat Generation on Bits of a Continuous Miner-Using Numerical and Experimental Approach. Dissertations and Theses, Gradworks.

[12] Mishra, B. and Khair, A.W. (2006) Numerical Simulation of Rock Indentation and Heat Generation during Linear Rock Cutting Process. Golden Rocks 2006, The 41st U.S. Symposium on Rock Mechanics, Golden, Colorado, 17-21 June 2006, 653-668.

[13] Hekimoglu, O.Z. and Ozdemir, L. (2013) Effect of Angle of Wrap on Cutting Performance of Drum Shearers and Continuous Miners. Transactions of the Institution of Mining and Metallurgy, 113, 118-122.

[14] Pryhorovska, T.O., Chaplinskiy, S.S. and Kudriavtsev, I.O. (2015) Finite Element Modeling of Rock Mass Cutting by Cutters for PDC Drill Bits. ShiyouKantan $Y u$ Kaifa/Petroleum Exploration and Development, 42, 888-892. https://doi.org/10.1016/S1876-3804(15)30087-2

[15] Wang, J., Zou, D. and He, R. (2006) Experimental Study on Force of PDC Cutter Breaking Rock. Procedia Engineering, 73, 258-263.

[16] Liu, S., Liu, Z., Cui, X. and Jiang, H. (2014) Rock Breaking of Conical Cutter with Assistance of Front and Rear Water Jet. Tunnellingand Underground Space Technology, 42, 78-86. https://doi.org/10.1016/j.tust.2014.02.002

[17] Menezes, P.L., Lovell, M.R., Avdeev, I.V. and Iii, C.F.H. (2014) Studies on the Formation of Discontinuous Rock Fragments during Cutting Operation. International Journal of Rock Mechanics and Mining Sciences, 71, 131-142. https://doi.org/10.1016/j.ijrmms.2014.03.019

[18] Chen, S., Arfele, R., Anderle, S. and Romero, J. (2013) A New Theory on Cutter Layout for Improving PDC Bit Performance in Hard and Transit Formation Drilling. SPE Drilling and Completion, 28, 338-349. https://doi.org/10.2118/168224-PA

[19] Deng, M., Wu, K. and Hu, W. (2014) Rock-Breaking Simulation and Experimental Analysis of PDC Bit Cutter. China Petroleum Machinery, 41, 970-972.

[20] Mazurkiewicz, D. (2000) Empirical and Analytical Models of Cutting Process of Rocks. Journal of Mining Science, 36, 481-486. https://doi.org/10.1023/A:1016620810143

[21] Liu, X.D. and Qu, J.L. (2010) Research on Main Geometric Parameters of PDC Bit Influencing On the Mechanical Behavior. Journal of Mechanical Design and Manufacturing, 5, 69-71. 
Submit or recommend next manuscript to OALib Journal and we will provide best service for you:

- Publication frequency: Monthly

- 9 subject areas of science, technology and medicine

- Fair and rigorous peer-review system

- Fast publication process

- Article promotion in various social networking sites (LinkedIn, Facebook, Twitter, etc.)

- Maximum dissemination of your research work

Submit Your Paper Online: Click Here to Submit

Or Contact service@oalib.com 